\title{
Who's helping to bring science to the people?
}

\section{With student numbers falling, we need more researchers to do public-outreach work.}

Sir - Your Commentary article "Weapon of mass attraction" (Nature 433, 357-358; 2005) highlighted poor participation by US scientists in public-outreach activities.

It may be interesting to look at the situation in France, where the reform of the national research agency, the CNRS, has led to the creation of a working group on the popularization of science, which I lead.

Preliminary data on activities carried out by the 10,403 CNRS scientists, from July 2003 to June 2004, show that threequarters of them did not get involved in any popularization, or public-outreach, activity during the year — taking this to mean writing a book or presenting a popular-science lecture or poster.

A closer look at the data reveals that efforts are unequally distributed: the most active $10 \%$ of scientists account for $70 \%$ of all public-outreach activity and the top $5 \%$ account for half.

A fit of the histogram of the number of activities per scientist produced a more precise picture. We discovered that a single Poisson distribution cannot fit all the data. This confirms that scientists do not constitute a homogeneous population.

The best fit we found requires three different Poisson distributions, which can be interpreted as three different sub-populations: the 'silent majority' (76\% of scientists, who do hardly anything); the 'open minority' ( $21 \%$, who carry out some activity once or twice a year); and the 'semi-professional popularizers' (3\% of scientists who carry out activities on average six times a year). Researchers in this active minority dedicate a significant fraction of their research time to the public, accounting for a third of all activities in bringing science to the people.

Policies aimed at getting scientists more involved in public outreach should perhaps be tailored to the three sub-populations we found. For example, those who do not yet carry out any public-outreach activities have to be convinced of the importance of doing so. The decline in student numbers seems to have persuaded more physicists to get involved in the World Year of Physics. The 'open minority' might be encouraged by access to simple tools for efficient public outreach, while the 'semi-professional popularizers' may have concerns about institutional rewards.

Contrary to expectations, our data suggest that age is not significant. We find that the average number of public-outreach activities is broadly constant with age, increasing moderately as scientists get older, from 0.45 activities a year for those aged $31-35$, to 0.7 a year at 56-60.

Our data also reveal variation among fields: the proportion of scientists carrying out public-outreach activities varies from $17 \%$ for general physics, chemistry and biology, to $30 \%$ for astrophysics and $41 \%$ for social sciences.

Interestingly, while the mean number of activities per scientist varies considerably from field to field (from 1.2 for social sciences to 0.3 for general physics, chemistry and biology), the productivity of active scientists is constant across all fields (close to 2.5 actions a year).

Finally, our data reveal that speaking at conferences on popular science is the most common activity (25\%), followed by writing newspaper articles (23\%) and giving radio or television presentations (17\%).

Again, there are variations across different disciplines. For example, much higher numbers of social scientists appear on radio or television $(61 \%)$. So any researcher willing to pursue television might be able to learn something from their colleagues in the humanities.

Pablo Jensen

Laboratoire de Physique de la Matière

Condensée et Nanostructures,

Université Lyon I,

69622 Villeurbanne Cédex, France

\section{Reviewers not attached to online submission}

Sir — John P. Moore's criticism, in Correspondence, of electronic journal submission, "Online submission makes authors do all the work" (Nature 433, 800; 2005), only examines the author-editor interaction. The poor peer reviewer also suffers from electronic manuscript submission.

I am generally happy to review papers relevant to my own expertise, unless I'm too busy. But papers forwarded as e-mail attachments almost invariably cause headaches when I am unable to open or print some or all of the associated illustrations. It recently took two days to find someone with the necessary knowhow and software to open and print a plate at publication size, yet it took me less than an hour to review the associated paper.

Given the choice, I always ask editors to send me a hard copy. I am never so free as to be able to review a paper immediately, so the delay of even intercontinental mail is not an inconvenience.

Worse still are some grant-awarding bodies. Recently, I couldn't review a proposal when asked by the US National Science Foundation. But just saying "No" by return e-mail is not acceptable. Instead, it is necessary to open the attachment and follow instructions to the "Decline" box. Steve Donovan

Department of Palaeontology,

Nationaal Natuurhistorisch Museum, Postbus 9517, NL-2300 RA Leiden, The Netherlands

\section{Funding shouldn't rely on competing death tolls}

Sir - I think it is important to note the irony in your News story, "Protest letter accuses health agency of biodefence bias" (Nature 434, 7; 2005), of researchers who shun the study of disease complaining that a US agency called the National Institutes of Health fails to fund them adequately.

I find it striking that those who protest against the funding of biodefence research are proposing instead that public-health menaces should be given the highest priority. By this standard, many of the letter's signatories should voluntarily return their funding for research on Bacillus subtilis, Escherichia coli and other nonpathogens so that it can be appropriately directed towards the obvious public-health threats of HIV and tuberculosis.

Although I disagree with their reasoning, I strongly agree that basic microbial research is so important, in and of itself, that its funding level should be not be reduced regardless of other concerns, whether arising from public health or bioterrorism. Using body counts ("Bioweapons agents cause, on average, zero deaths per year") may be useful in the short term to frame the debate, but I fear they will be damaging in the long run. How many of us want to be asked, when our next grant is reviewed: "How many people did your bug kill last year?”. I certainly don't.

If basic research is relevant to the health of the nation, then make the case that it is so. The current approach will only leave funding levels vulnerable to the next media sensation or hysterical distraction. David Hilbert

Department of Anatomy and Cell Biology, PひS 12-517, Columbia University, New York, New York 10032, USA 